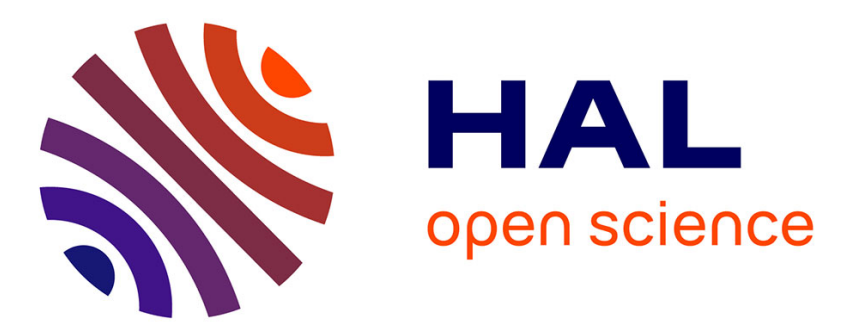

\title{
Analyzing railroad congestion in a dense urban network through the use of road traffic network fundamental diagram concept
}

Pierre-Antoine Cuniasse, Christine Buisson, Joaquin Rodriguez, Emmanuel Teboul, David de Almeida

\section{To cite this version:}

Pierre-Antoine Cuniasse, Christine Buisson, Joaquin Rodriguez, Emmanuel Teboul, David de Almeida. Analyzing railroad congestion in a dense urban network through the use of road traffic network fundamental diagram concept. TRB 2014 - Transportation Research Board 93rd Annual Meeting, Jan 2014, WASHINGTON D.C, United States. 15 p. hal-01411678

\author{
HAL Id: hal-01411678 \\ https://hal.science/hal-01411678
}

Submitted on 7 Dec 2016

HAL is a multi-disciplinary open access archive for the deposit and dissemination of scientific research documents, whether they are published or not. The documents may come from teaching and research institutions in France or abroad, or from public or private research centers.
L'archive ouverte pluridisciplinaire HAL, est destinée au dépôt et à la diffusion de documents scientifiques de niveau recherche, publiés ou non, émanant des établissements d'enseignement et de recherche français ou étrangers, des laboratoires publics ou privés. 


\section{Analyzing railroad congestion in a dense urban network through the use of road traffic network fundamental diagram concept}

Pierre-Antoine Cuniasse (corresponding author)

Universite de Lyon, F-692, Lyon France

SNCF, Transilien, F-75012 Paris

IFSTTAR, LICIT, F-69518 Vaux en Velin

IFSTTAR, ESTAS, F-59666 Villeneuve d'Ascq phone: 33651420431

pierre-antoine.cuniasse@sncf.fr

Christine Buisson

Universite de Lyon, F-692, Lyon France

IFSTTAR, LICIT, F-69675 Bron

ENTPE, LICIT, F-69518 Vaux en Velin

phone: 334720477 13, fax: 33472047713

christine.buisson@entpe.fr

Joaquin Rodriguez

Universite de Lille-Nord de France, France

IFSTTAR, ESTAS, F-69666 Villeneuve d'Ascq

phone: 33320438332

joaquin.rodriguez@ifsttar.fr

Emmanuel Teboul

SNCF, Transilien, F-75012 Paris

phone: 33153258278

emmanuel.teboul@sncf.fr

David de Almeida

SNCF, Direction Innovation Recherche, F-75012 Paris

phone: 33157236381

david.de_almeida@sncf.fr 
Paper submitted to TRB Annual Meeting 2014 July 31, 2013

3316 words +8 figure $(s)+2$ table $(s) \Rightarrow 5816$ 'words' 


\section{ABSTRACT}

Transilien, the branch of SNCF in charge of operating the main urban railroad network in the area of Paris, faces a regular increase of passengers flows. The planning of railway operations is made carefully: simulation runs permit to assess the timetable stability. However, many disturbance appears and cause trains delays. Due to the nature of the railroad network those delays are cumulative and an on-line update of the timetable is not always successful in maintaining the trains schedule. In this tensed context, operators are searching solutions to better use the infrastructure capacity and better service quality. A needed step towards this objective is a better understanding of the phenomena of disruptions. In particular because the expansion of congestion is not clearly understood until now. This paper explores the possibility to transpose a traffic flow theory tool, the network fundamental diagram, in the field of dense railroad traffic. Railroad traffic is different of road traffic by many ways: railways are a planned system, traffic volume does not satisfy the continuum hypothesis, stations force stops and the signalization system brings a discrete behavior. Despite those big differences we show how to build a network fundamental diagram for a railroad system and how to interpret some obtained shapes for those diagrams. These diagrams gives us some means to compare planned and reality. We also identify the limits that need to be overcome to take benefits of the road traffic tools in railroad traffic analysis. 


\section{INTRODUCTION}

In dense urban regions, the railway system is frequently operating not as scheduled. Indeed, it is a common fact that theoretical schedules of trains are not respected and that in reality, the train circulation system is operating differently than what is planned. Deviations from schedules are observed in two cases: 1/ exceptional situations with the occurrence of an external event (due to meteorological conditions for example) 2/ everyday situations where the schedule is not strictly respected (for example a small delay in one station induces a bigger in the next one). Whatever the cause of the delay, railroad users are impacted and this is decreasing their confidence into railway mode, destroying therefore the efforts of modal shift to a more energy-efficient mode.

To face this problem, railway companies add margins to the theoretical schedule to increase the probability of schedule adherence; however, the added margins reduce the availability of track capacity for additional rail transport services. $(1,2,3)$. Afterwards, the robustness of the obtained schedule is frequently evaluated with microscopic simulation tools $(4,5)$. Nevertheless, those increased efforts towards more realistic theoretical schedules are not effective. This is even truer if, like in dense urban regions, both political orientations toward sustainable transportation and the economic grow cumulate in an increasing demand.

Therefore, the lack of positive results for those approaches and the absence of willpower for building an explanatory model leads us to search for another intellectual scheme to reduce the differences between observed and planned schedules in urban dense railway operations. Analysis tools initially developed for other congested transportation modes can be considered and their transfer to the railway context has to be examined. For the present research we choose the road transportation mode and proceed according to a three steps procedure: 1/ use the analysis methods applied to road traffic data to quantify the impact of congestion on the railway system, $2 /$ develop models inspired by road traffic models, 3 / make a cross comparison between modelling results and observations to test the validity of those models.

As a start, we consider a recently re-discovered tool for road traffic data analysis (the network fundamental diagram) and study its transfer to the case of the railway network of the Paris region, one of the most congested railway systems in Europe. The main aim of this paper is therefore to build the network fundamental diagram of railway lines (NFD-R) and to study the link between congestion and the shape of the NFD-R.

The paper is organized as follows. From a brief literature overview of road traffic network fundamental diagrams, we identify the main reported causes of dispersion of their points. A description of the railroad network and of the data collection technique is thus given. The results and their analysis is presented before a discussion. The paper ends with conclusions and recommendations for future research.

\section{NETWORK FUNDAMENTAL DIAGRAM : STATE OF THE ART FOR ROAD TRAFFIC NETWORKS}

For more than half a century, road traffic is measured through local detectors (double electromagnetic loop detectors) that are able to measure at a given point the time between the passing of two successive vehicles and the speed of each of them. Macroscopic variables characterizing the traffic 
flow seen as a whole can be extracted from those observations. Those variables are the spatial mean speed and the flow (number of vehicles passing the detector during a given period). The density (number of vehicles for a given length of link) can also be extracted through a rough approximation of the fraction of time during which the loop is occupied by a vehicle.

Expanding those measurements to compute mean accumulation and flow of vehicles for a given period over a whole network is not a new idea. After the initial publication of this idea in (6), Herman and Prigogine propose in ( 7 ) a formulation of the relationship between mean speed and mean concentration. This idea was further developed in many papers of those authors and network and its total accumulation. Those papers are devoted to the free flow part of the diagram: the mean flow increases with the accumulation. In particular(8) evokes the possibility of random events of lane blockages in a rectangular grid urban network simulated with NETSIM. The bigger the ratio between time with lane blockage and total simulation time is, the lower the slope of the relationship between global flow and global accumulation was not observed.

In (9) Daganzo hypothesized that above a given threshold in total accumulation (critical value of accumulation), an increase of this accumulation leads to a decrease of the total flow. This was experimentally observed for the first time by Geroliminis and Daganzo one year after(10, 11) lation averaged during periods of typically a few minutes on a (sub-) network was initially named by Daganzo and Geroliminis Macroscopic Fundamental Diagram. Following the authors of (12) in their introduction, we do prefer the term "Network fundamental diagram" which is to our opinion more precise, "macroscopic" referring to the variables (flow and concentration) by opposition with the microscopic ones like inter-vehicular time or individual speed.

Since 2008, network fundamental diagram exploration, (driven either experimentally or analytically or through simulation data), has known many developments as a particular sub domain of road traffic flow studies. A recent and promising direction of research is the control of the reservoir and controlling the entry and exit flows of those reservoirs to decrease congestion (see for example $(13,14))$. Recently, one of these groups of authors proposed a method to partition the network into homogeneous zones to reduce the scatter of the diagram and increase the network controllability (15).

Some authors study the impact of detectors types and location either on experimental data (see for example(16)) or on analytical expressions (see(17)). More generally, we have to stress that there is common agreement among various authors that the measurement methodology impact significantly the shape of the NFD. of density among links at a given instant. This can be derived from data (18) or from simulation, in particular when looking at the traffic assignment impacts (19).

Globally, as was first put into evidence in (16) and further on mentioned in (20), the NFD 45

for a highway network is not well defined in the sense of (15). Indeed, the congestion level of 
the highway network is not homogeneous. In recently published papers, the impact of combining various traffic states among various parts of the considered network for computing the NFD has been explored in parallel by two teams: (12) and also by (21). work fundamental diagram, were seldom transposed in other congested modes of transportation. A paper present the adaptation of Personal Car Equivalent concept to take into account the difference in mechanical abilities among trains in computing the capacity of a railroad (22). We will now present the transposition of the concept of Network Fundamental Diagram in the case of the dense

\section{DATA AND METHODS}

\section{Network}

With a population of 11.5 millions inhabitants, Paris urban area is the most dense conglomeration area is covered with two railroad networks: the subway and the RER network which transports about 7 millions of passengers a day (RER stand for Local Express Network). For this paper we choose to focus on the SNCF (french national railroad) operated part of the RER. Today, the growing demand makes the RER over-saturated. Figure 1 represents the RER network which is The interest of those lines lies on their very high train traffic.

\section{Data}

Beacons are located over the railway network and detect the passage of trains and record their identifiers and events times. The beacon density over the network is variable and its order of magnorthbound of B line between Paris gare du nord, CDG Aeroport terminal 2 and Mitry Claye, and the central section of $\mathrm{C}$ line between Champ de Mars and Choisy le Roi. The results of this paper are based on a SNCF database which gathers all the informations from the beacons and the corresponding theoretical times of passage over the beacons. Since each lines also got two directions, special traffic event (planned public work...) are rejected. In the end, thirty-three days of data are available for B line and thirty-four for $\mathrm{C}$ line. The list of days used for each line is presented in table 2 .

\section{RESULTS AND ANALYSIS}

\section{First observations of the network fundamental diagram for railroad}

For one day and one set of data, the number of beacon events over time and the number of trains were counted and filtered with a running average (window time: 10 minutes, step time: 1 minute). We consider that at any given instant, the total number of trains present in a line is directly proportional to the average train concentration. We further assume that the number of trains passing over all the beacons of a line during a given period is proportional to an average flow on the same section. Note that this is not completely true in our case, since the distance between two consecu- 


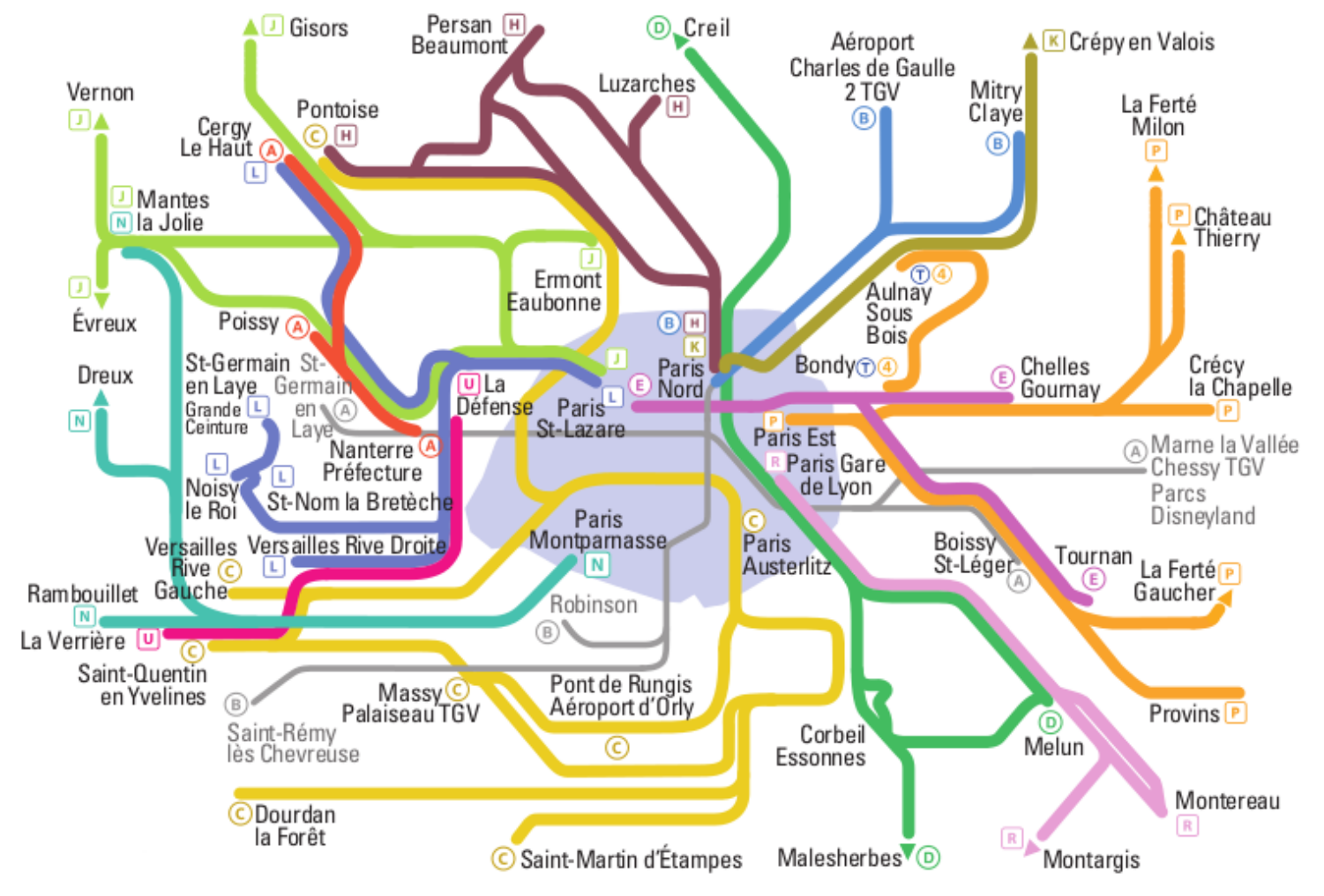

FIGURE 1 The Paris-area RER network, where the SNCF parts are in color. The shaded area is the Paris inner city. The scale is not respected.

tive beacons is not homogeneous over the line. Then, when plotting the number of events reported by all the beacons of a line against the number of trains of this line during the same period, we construct the NFD-R (Railroad) diagram.

Figure 3 presents the NFD-R for 2 lines: the B line - North direction (left column) and the $\mathrm{C}$ line - West direction (right column). To facilitate incident identification, markers were colored according to hours. The top diagrams of figure 3 represent the planned situation ( $\mathrm{T}$ stands for Theoretical) on a typical day. The diagrams below present the results obtained in operation for various days. Depending on the day, a dispersion is observed or not. In any cases, most points are aligned along a (slopped) line. We now examine the slope of the diagrams and, if present, the possible causes of spreading.

We can see from figure 3 that various shapes were observed for real diagrams. We visually selected days and lines where the realized NFD-R was almost linear (for example, diagrams (B-R2), (B-R3), (C-R2) and (C-R3) from figure 3 were rejected). This set of NFD-R is further referred as the "filtered NFD-R". The numbers of filtered NFD-R are given in table 2. For those days and those lines, we made two polynomial regressions called $y_{1}$ and $y_{2}$ (see figure 4 ). Some of 
TABLE 1 Details of analysed sections: the North-B line got a "Y" shape which is here described in three sections. This table provide the station name, the distance between consecutive stations, and the number of beacons in each station sector. This number can change according to the direction.

\begin{tabular}{|c|c|c|c|c|c|c|c|c|c|c|c|}
\hline \multicolumn{3}{|c|}{ Section 1 (14km) } & \multicolumn{3}{|c|}{$\begin{array}{c}\text { Ligne B } \\
\text { Section } 2(14 \mathrm{~km})\end{array}$} & \multicolumn{3}{|c|}{ Section 3 (12km) } & \multicolumn{3}{|c|}{$\begin{array}{c}\text { ligne C } \\
\text { Central Section }(16 \mathrm{~km})\end{array}$} \\
\hline \multirow{2}{*}{$\begin{array}{c}\text { Station } \\
\text { Length }(\mathrm{m})\end{array}$} & \multicolumn{2}{|c|}{ beacon } & \multirow{2}{*}{$\begin{array}{c}\text { Station } \\
\text { Length }(\mathrm{m})\end{array}$} & \multicolumn{2}{|c|}{ beacon } & \multirow{2}{*}{$\begin{array}{c}\text { Station } \\
\text { Length }(\mathrm{m})\end{array}$} & \multicolumn{2}{|c|}{ beacon } & \multirow{2}{*}{$\begin{array}{c}\text { Station } \\
\text { Length }(\mathrm{m})\end{array}$} & \multicolumn{2}{|c|}{ beacon } \\
\hline & north & south & & north & south & & north & south & & west & east \\
\hline gare du nord & 1 & 1 & Aulnay /s Bois & 1 & 1 & Aulnay /s Bois & 1 & 1 & Champ de Mars & 3 & 3 \\
\hline 4305 & & & 3436 & & & 3000 & & & 974 & & \\
\hline La Plaine SdF & 1 & 1 & Sevran Beaudottes & 1 & 1 & Sevran Livry & 1 & 1 & Pont de l'Alma & 1 & 1 \\
\hline 1782 & & & 1950 & & & 2512 & & & 976 & & \\
\hline La Courneuve & 3 & 3 & Villepinte & 1 & 1 & Vert Galant & 1 & 1 & invalides & 2 & 3 \\
\hline 3053 & & & 1200 & & & 2819 & & & 1075 & & \\
\hline Le Bourget & 3 & 3 & Parc des expositions & 1 & 1 & Villeparisis & 1 & 1 & Orsay & 2 & 3 \\
\hline 2237 & & & 6585 & & & 3899 & & & 1601 & & \\
\hline Drancy & 1 & 1 & CDG1 & 1 & 1 & Mitry Claye & 2 & 2 & St-Michel & 1 & 1 \\
\hline 1345 & & & 1132 & & & & & & 2233 & & \\
\hline Le Blanc Mesnil & 1 & 1 & CDG2 & 1 & 1 & & & & gare d'Austerlitz & 4 & 3 \\
\hline 1239 & & & & & & & & & 1640 & & \\
\hline \multirow[t]{9}{*}{ Aulnay /s Bois } & 1 & 2 & & & & & & & Bibl. F.Mitterand & 3 & 6 \\
\hline & & & & & & & & & 1822 & & \\
\hline & & & & & & & & & Ivry s/ Seine & 1 & 1 \\
\hline & & & & & & & & & 1749 & & \\
\hline & & & & & & & & & Vitry s/ Seine & 1 & 2 \\
\hline & & & & & & & & & 2035 & & \\
\hline & & & & & & & & & Les Ardoines & 1 & 1 \\
\hline & & & & & & & & & 2072 & & \\
\hline & & & & & & & & & Choisy le roi & 3 & 2 \\
\hline
\end{tabular}

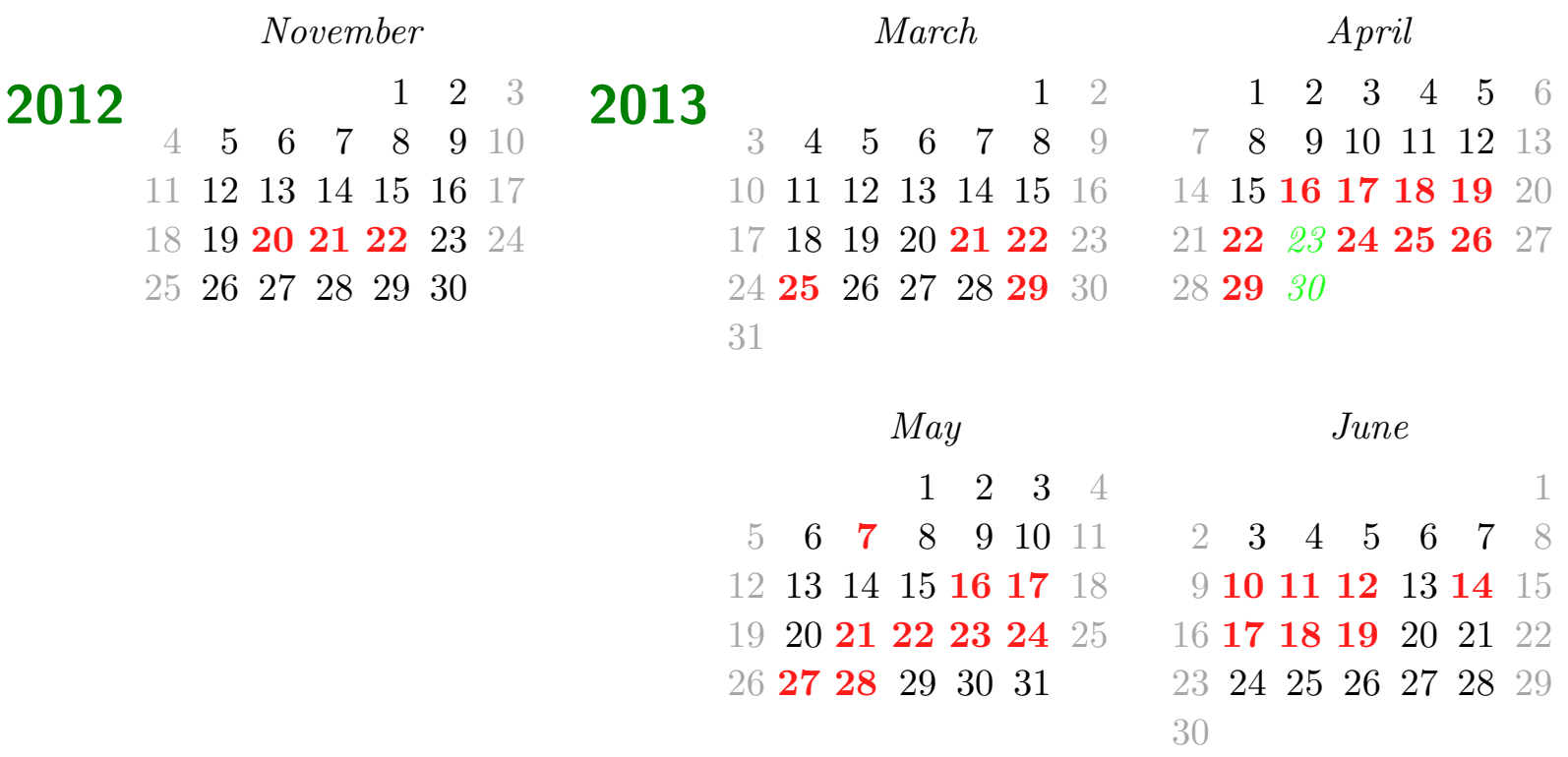

FIGURE 2 List of days selected for analysis. The red-bold days are for $\mathrm{B}$ and $\mathrm{C}$ lines and the green-italic ones for $\mathrm{C}$ line only.

these regression are represented in figure 5. 

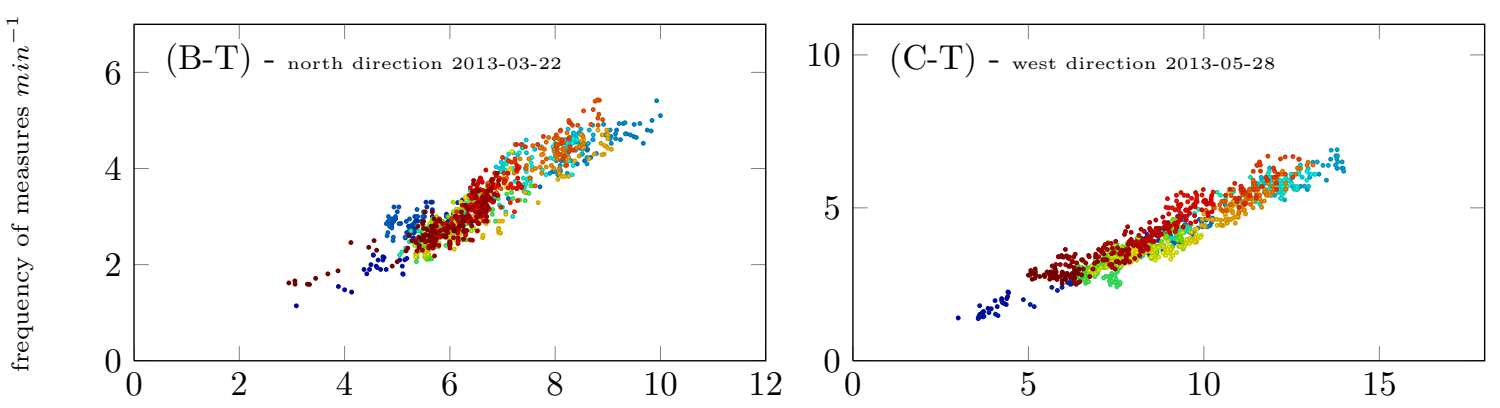

hours
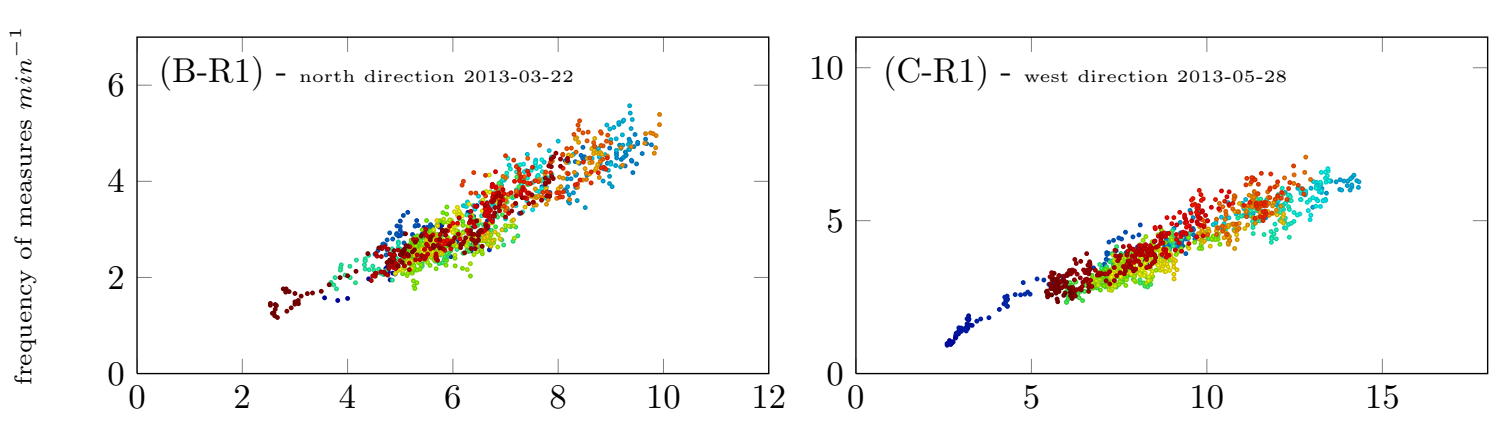

hours
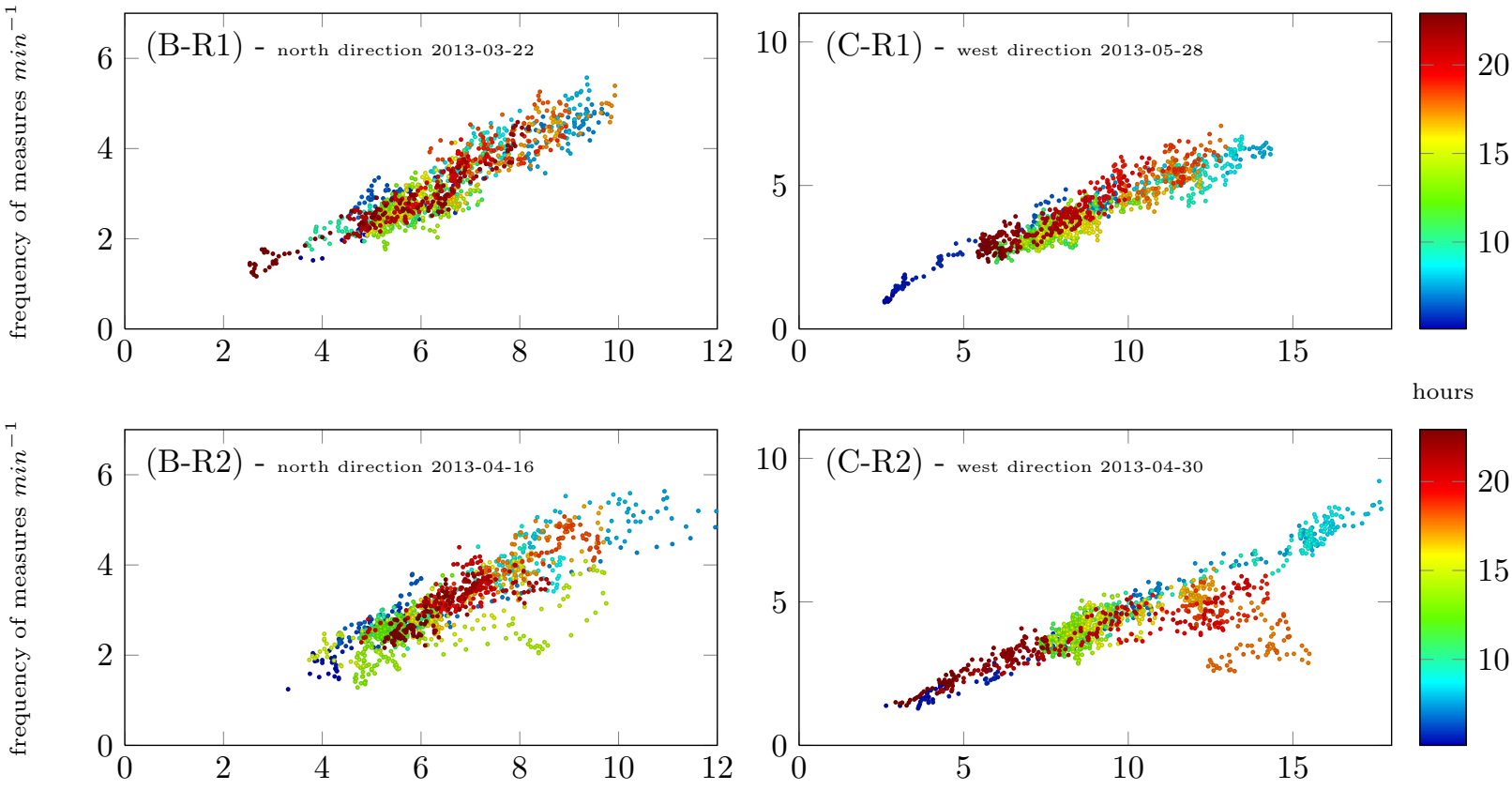

hours
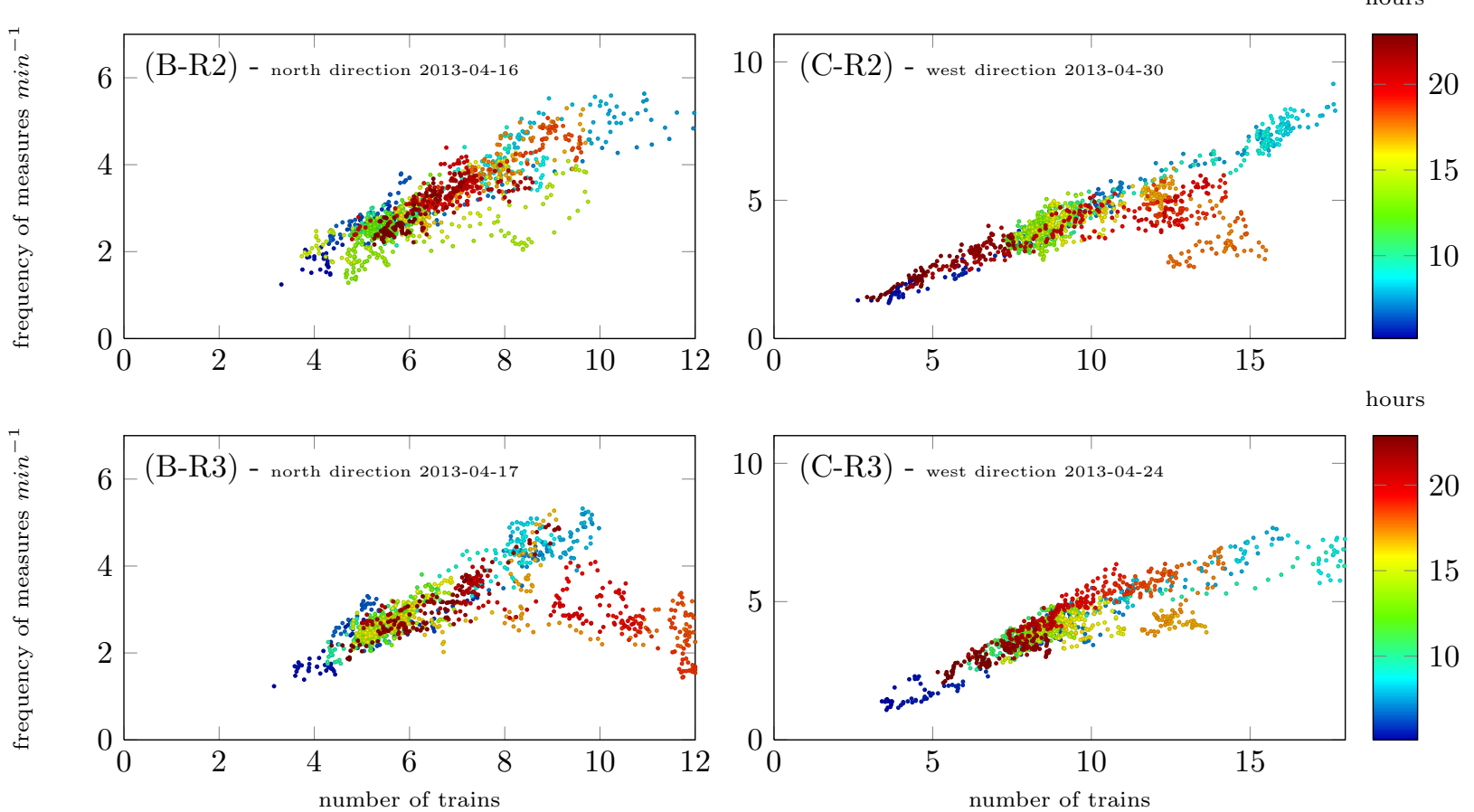

20

FIGURE 3 examples of NFD-R. (B-T) \& (C-T) represent theoretical diagrams, (B-R1), (B-R2), (B-R3), (C-R1), (C-R2) and (C-R3) represent real diagrams.

Since the second regression model $y_{2}$ is not linear, the R-value is not a good choice to compare the two relationships and the $\chi^{2}$ residuals are a better choice. Table 2 presents the mean value of $\chi^{2}$ for each cases; the two relationship gives very similar results. The linear regression was rejected because there is a strong reason for the curve to pass through the $(0,0)$ point (zero 

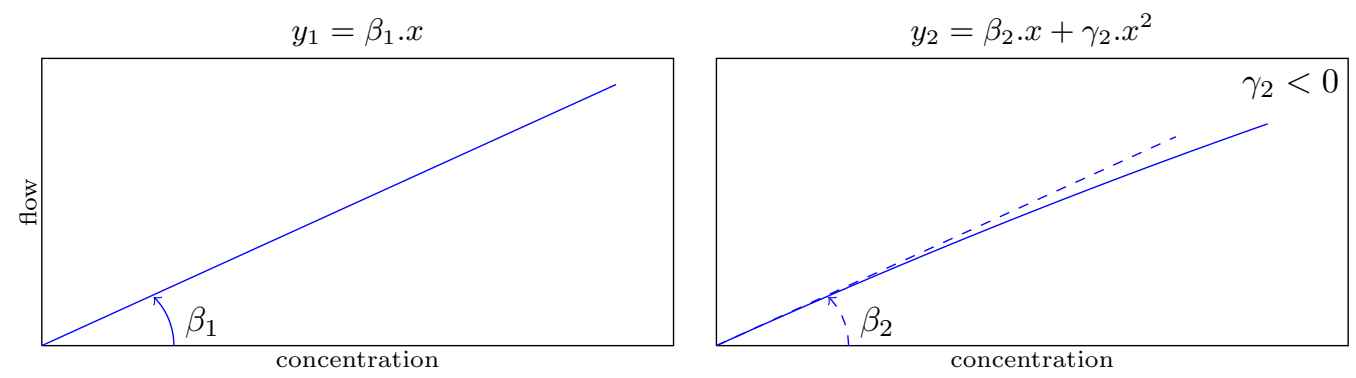

FIGURE 4 The two types of fit; $y_{1}$ is a proportional fit where the slope $\beta_{1}$ represents an average speed and is expressed in $\left[\right.$ measure. $\mathrm{min}^{-1} \cdot$ train $\left.^{-1}\right]$; $y_{2}$ is a quadratic fit where $\gamma_{2}$ gives a curvature depending to its sign. A negative $\gamma$ implies a concave curve which means that the average speed decrease when the train concentration increase.

trains implies zero beacon's measurements).

TABLE 2 Average value for the residuals in different cases.

\begin{tabular}{|c|cccccccc|}
\hline Line direction & B south T & B south R & B north T & B north R & C east T & C east R & C west T & C west R \\
\hline Days & 16 & 16 & 14 & 14 & 24 & 24 & 24 & 24 \\
y'1 & 0.0116 & 0.0129 & 0.0101 & 0.0102 & 0.0117 & 0.0162 & 0.0090 & 0.0136 \\
y'2 & 0.0108 & 0.0127 & 0.0089 & 0.0101 & 0.0113 & 0.0160 & 0.0087 & 0.0126 \\
\hline
\end{tabular}

\section{Comparison between theoretical and real NFD-R}

It is well known that the slope of the left, uncongested part of a fundamental diagram is homogeneous to the speed in free flow conditions. To estimate a proxy for the railroad network, we use the $\beta_{1}$ value which is homogeneous to a speed. $\beta_{1}$ (from $y_{1}$ ) is then used to compare theoretical and realised NFD-R over all NFD-R (all diagrams must be included to evaluate the global performance of a day; the $\beta_{1}$ value represents in this case a performance indicator and not striclty the slope of a graph). Figure 6 represents the frequency of the difference between the $\beta_{1}$ values obtained for the actual and planned timetables $\left(\beta_{\text {realised }}-\beta_{\text {theoretical }}\right)$ for the two studied lines. This figure shows that the trains of B line (resp. $\mathrm{C}$ line) go often more slowly than planned. $\mathrm{C}$ line appears also more constant than B line. The lower size of the B line filtered sample compared to the $\mathrm{C}$ line might be an explanation for the higher spreading. The lower values of the slopes for the realized NFD-R compared to the theoretical NFD-R reflects a lower operating speed of the system, compared to what is planned. This has to be linked with the results obtained in simulations and presented in (8), where the slope of the NFD of a urban road traffic network is lower when then duration of red phases of traffic lights is higher.

Coming back to filtered NFD-R, we can see in figure 7 that theoretical and real diagrams do not fit with the same shape when considering the quadratic regression model $y_{2}: \gamma_{2}$ value are nearly always bigger for the theoretical timetables than for the timetables resulting from operations. 

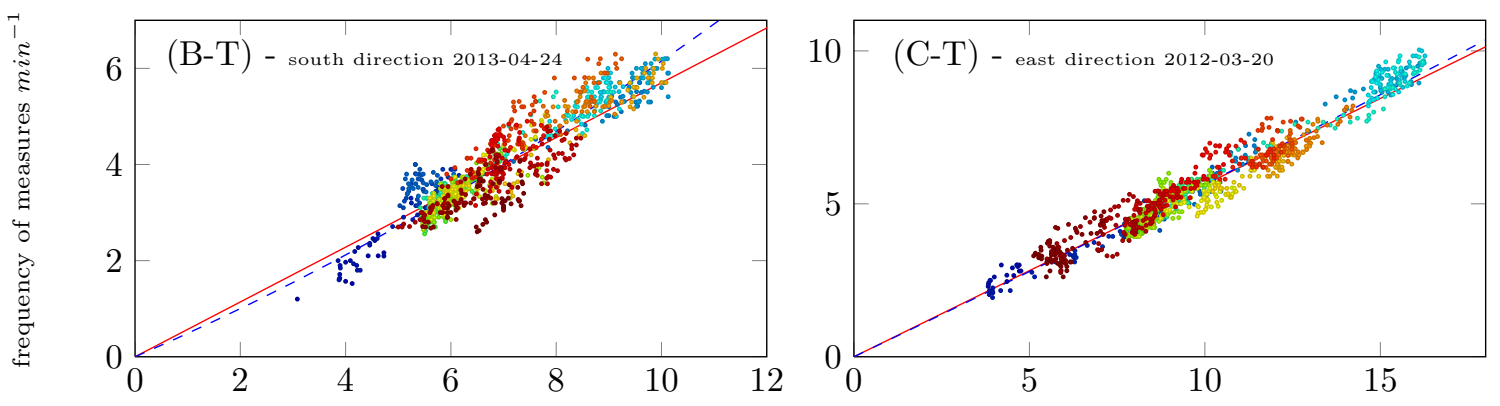

hours
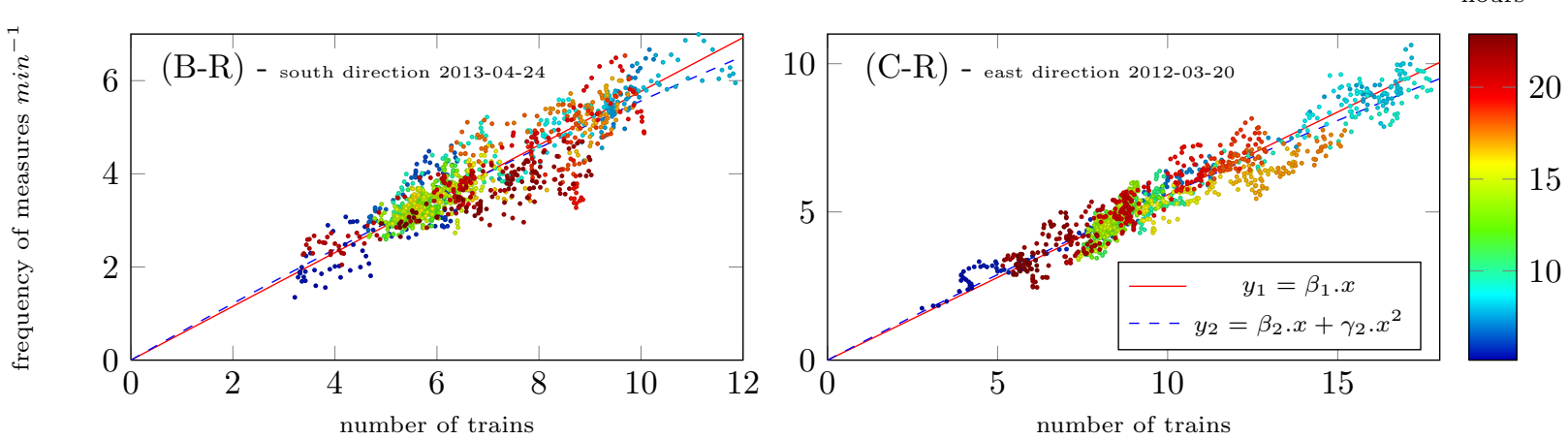

\begin{tabular}{|c|cc|ccc|}
\hline$y=a+b . x+c . x^{2}$ & \multicolumn{3}{|c|}{$y_{1}$} & \multicolumn{3}{|c|}{$y_{2}$} \\
\hline$(\mathrm{B}-\mathrm{T})$ & $\beta_{1}=.570$ & res $=.0113$ & $\beta_{2}=.472$ & $\gamma_{2}=.0143$ & res $=.0106$ \\
$(\mathrm{~B}-\mathrm{R})$ & $\beta_{1}=.577$ & res $=.0131$ & $\beta_{2}=.621$ & $\gamma_{2}=-.0064$ & res $=.0130$ \\
$(\mathrm{C}-\mathrm{T})$ & $\beta_{1}=.563$ & res $=.0118$ & $\beta_{2}=.550$ & $\gamma_{2}=.0014$ & res $=.0115$ \\
$(\mathrm{C}-\mathrm{R})$ & $\beta_{1}=.558$ & res $=.0147$ & $\beta_{2}=.596$ & $\gamma_{2}=-.0038$ & res $=.0144$ \\
\hline
\end{tabular}

FIGURE 5 examples of NFD-R, fitted with two mathematical relationship. (B-T) and (B$R)$ : theoretical and real NFD-R for the $B$ line in south direction. (C-T) and (C-R): theoretical and real NFD-R for the $\mathbf{C}$ line in east direction. $\beta=\left[\right.$ min $^{-1}$. train $\left.^{-1}\right], \gamma=\left[\right.$ min $^{-1}$. train $\left.^{-2}\right]$
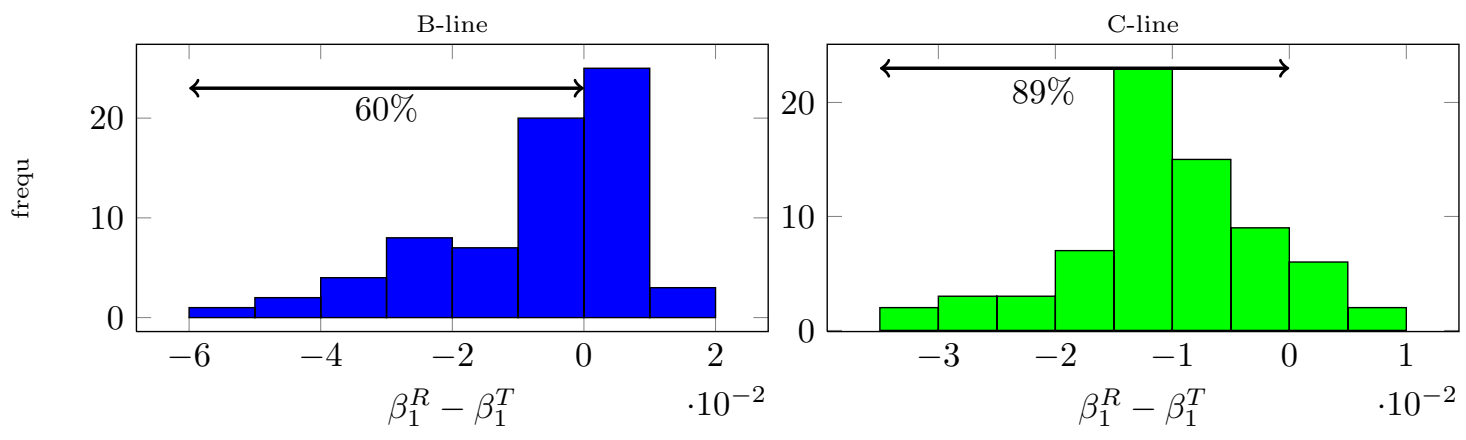

FIGURE 6 Comparison of $\beta$ value in $y_{1}$ fit for all NFD-R. For B line and for $60 \%$ of days $\beta_{R}<\beta_{T}$. For $\mathbf{C}$ line and for $\mathbf{8 9 \%}$ of days $\beta_{R}<\beta_{T}$.

\section{Impact of abnormal conditions of operations of the railroad network}

The local fundamental diagram (FD) represents the traffic flow function of the concentration on a single point of a network. The figure 8.a presents the theoretical FD of operations of the trains for a network without stations. Traffic regulation over the French Network rely on blocking. The points 

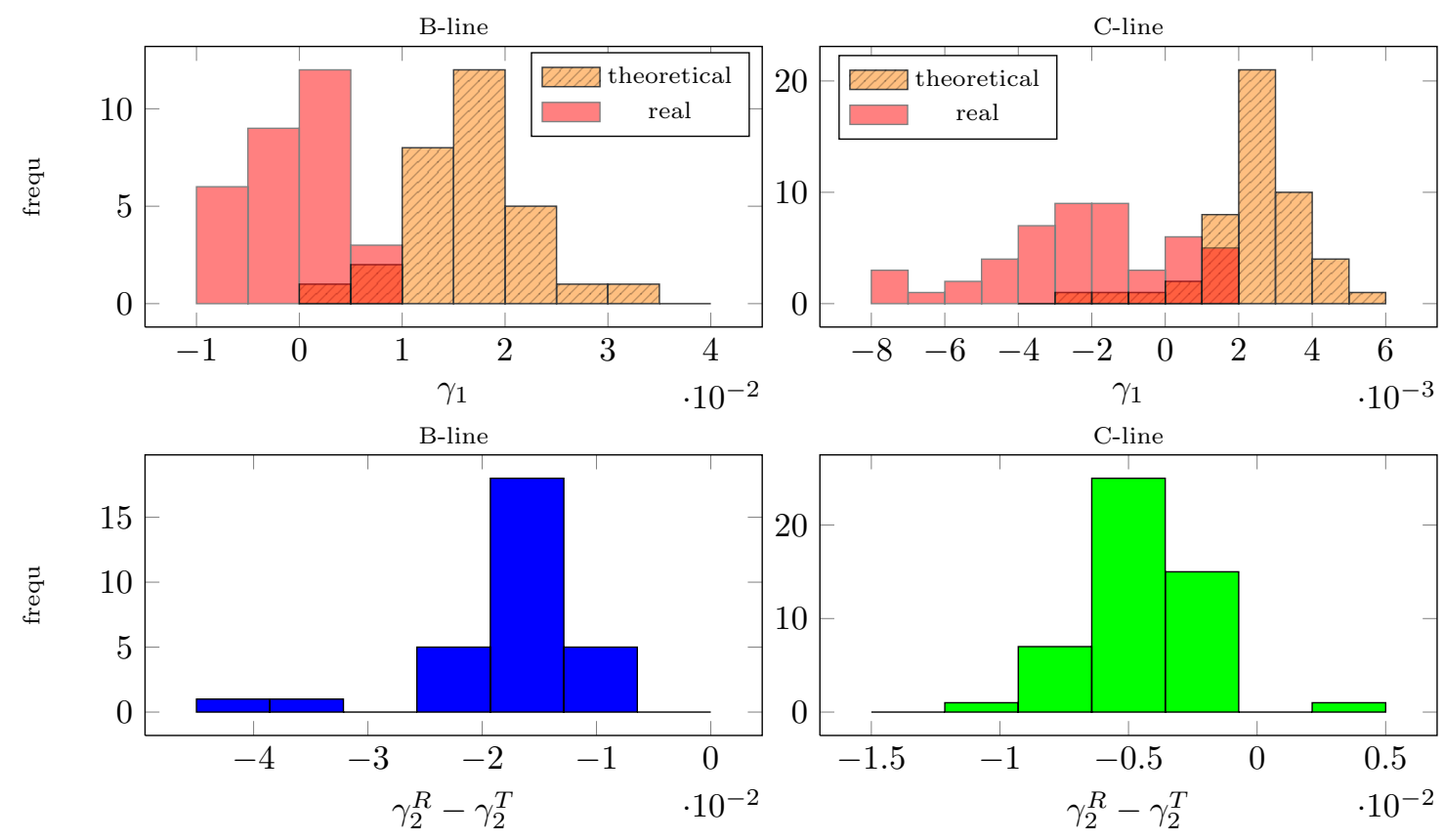

FIGURE 7 Comparison of $\gamma$ value in $y_{2}$ fit for filtered NFD-R

$\mathrm{U}, \mathrm{C}$ and $\mathrm{FC}$ of figure 8.a illustrate respectively three behaviours corresponding to three block aspects. Note that this FD is only theoretical for the moment. However, it can help us to construct theoretically a fictitious network fundamental diagram (see figure 8.b). In this NFD, the observed points are the result of a combination of various states of FD. If some trains do not operate in the free flow part of the FD, the NFD will not be linear. The figure 8.b illustrates this in the case of a combination of two different states of the network: points $\mathrm{B}$ and $\mathrm{C}$ of this figure are a combination of points b1 and b2 and $\mathrm{c} 1$ and $\mathrm{c} 2$ respectively. Logically, the point $\mathrm{A}$, resulting of two free flow states, is located in the free flow part. Figure 8.b is valid only for the case of a railroad network without stations. Nevertheless, we can observe on figure 4, for the case B-R3 points located below the sloped line associated with free flow operations. A first exploration has shown that in some cases, the occurrence of those abnormal points is linked in time with unplanned events. We have to better establish this point and to look at the impact of the stations and the accelerations they generate on the NFD-R.

\section{DISCUSSION AND CONCLUSION}

We have shown in this paper that a network fundamental diagram (NFD-R) can be built for dense railroad Systems. This diagram is usually constructed for road traffic network both urban or freeways, and the literature is numerous where analysis of its shape is presented. Here we proposed a way to build it from identification by beacons of the passing of trains and we applied it to two lines where trains frequency is particularly high. With this diagram, We highlight the existence of congestion phenomena. For most of the days, the slope of the NFD-R, which is an equivalent of the average speed, is lower than planned. This congestion phenomenon can appear in several ways: the first is discussed in this article and consist in a simple decrease of the speed while a NFD-R still exhibits a linear shape. On some of the NFD-R, on the contrary, we observe another shape, with dots below the sloped line. Those points will be analyzed in a further publication. 
a/

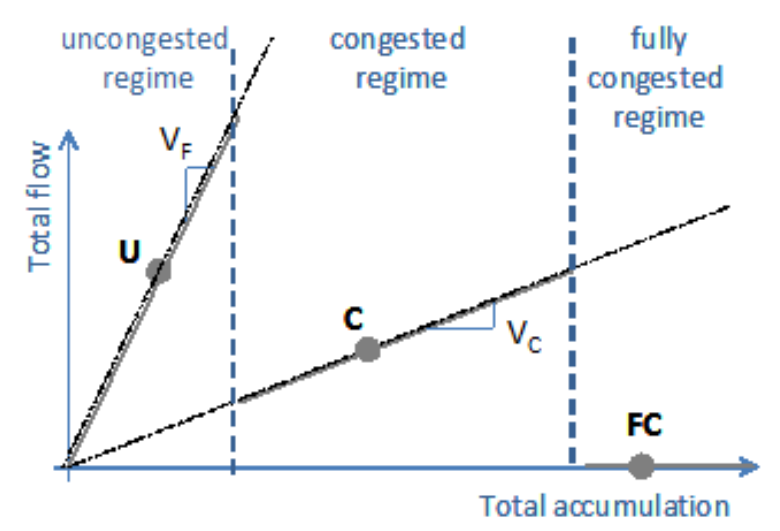

b/

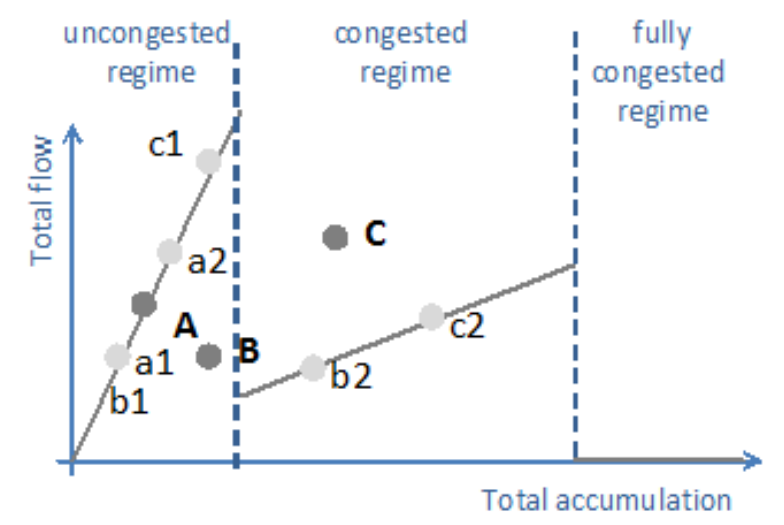

FIGURE 8 local (a) and network (b) theoretical fundamental diagrams of railroad operations in absence of stations. The bold lines of figure a presents the various equilibrium states associated with the train operations blocking rules. Three states are presented; uncongested when trains operates with a free flow speed, congested states, where the speed is strictly limited, and the fully congested points where the trains are stopped. In figure b, three points illustrates the network points associated with two states. Point $A$ is a combination of uncongested states, whereas points $B$ and $C$ are the combination of one uncongested and one congested state.

For the first category of days, we proposed two polynomials fits (one linear and one parabolic, both with a null value at origin). Regarding the residuals, they gives similar results. We observed that the quadratic model realized a small improvement over the linear one. Nevertheless, figure 7 shows a difference of curvatures between theoretical and real diagrams. We get positive values of $\gamma$ (especially for theoretical NFD-R) when we expected it to be null or negative. An hypothesis is that the planning process leads to an optimistic timetabling where trains are asked to go faster when their concentration increases. If validated, a light on the timetabling process should be helpful to understand these counter-intuitive results.

The research presented in this paper was only a first step of a larger project. The research directions to explore now are numerous. Among them one can cite a better exploration of the data: a more precise study must be undertaken prior to eliminate the influence of variable beacons density and reinforce our results. An exploration of the data of other lines will be needed to confirm the validity of our first results. Also the database of unplanned events has to be examined jointly with the points of the NFD-R located below the slope line. Simulating at a large scale a railroad network with stations and realistic decelerations and acceleration will permit us to better understand the real NFD-R. We might also in a farer future explore through the NFD-R tool the feasibility of using cordon regulations to better cope with undesired congestion. The transposition of the recent findings of road traffic theory might help us in finding better ways of identifying and reducing congestion if the Paris suburban railroad network, provided that we keep in mind the 
significant differences among the two modes.

Acknowledgements

This research is conducted with the benefit of a PhD grant from Agence Nationale de la Recherche Technologique, France. Authors want to thank Ludovic Leclercq and Winnie Daamen for fruitful

\section{REFERENCES}

[1] UIC, Links between railway infrastructure capacity and the quality of operations. International Union of Railways, , No. UIC code 405, 1996.

[2] UIC, Capacity. International Union of Railways, , No. UIC code 406, 2004.

[3] Goverde, R. M. P., Punctuality of Railway Operations and Timetable Stability Analysis. Ph.D. thesis, Delft University of Technology, 2005.

[4] Nash, D., A. \& Hurlimann, Railroad simulation Using OpenTrack. In Proc. of the 9th COMPRail conference (Computers in Railways IX), 2004.

[5] Radtke, L. B. J., A., Handling of railway operation problems with RailSys. In WCRRProceedings, Koln, 2001.

[6] Godfrey, J. W., The Mechanism of a Road Network. Traffic Engineering and Control, , No. Vol. 11, No. 7, pp.323-327, 1969.

[7] Herman, R. and Prigogine, A two-fluid approach to town traffic. Science, , No. 204, 148-15, 1979.

[8] Mahmassani, J. C. W., H. S. and R. Herman., Investigations of Network-Level Traffic Flow Relationships: Some Simulations Results. Transportation Research Record 971, , No. pp 121-130, 1984.

[9] Daganzo, Urban Gridlock: Macroscopic modeling and mitigation approaches. Transportation Research B, , No. 41(1), 49-62, 2007.

[10] Geroliminis, a. C. F. D., N., Existance of Urban-Scale Macroscopic Fundamental Diagrams: Some Experimental Findings. Transportation Research Part B, , No. 42(9), 759-770, 2008.

[11] Geroliminis, a. C. F. D., N., Macroscopic Modeling of Traffic in Cities. Transportation Research Borad, , No. No. 86, 2007.

[12] Saberi, M. and H. S. Mahmassani, Exploring the Properties of Network-wide Flow-Density Relations in a Freeway Network. Transportation Research Record, , No. No. 2315, pp. 153163., 2012.

[13] Haddad, G. N., J., On the stability of traffic control in two-region urban cities. Transportation Research B, , No. 46(9), 1159-1176, 2012. 
[14] Keyvan-Ekbatani, K. A. P. I. P.-M., M., Exploiting the fundamental diagram of urban networks for feedback-based gating. Transportation Research B, , No. 46(10), 1393-1403, 2012.

[15] Ji, Y. and N. Geroliminis, On the spatial partitioning of urban transportation networks. Transportation Research B, , No. 46(10), 1639-1656, 2012.

5 [16] Buisson, C. and C. Ladier, Exploring the Impact of the Homogeneity of Traffic Measurements on the Existence of Macroscopic Fundamental Diagrams. Transportation Research Record, 2009.

[17] Courbon, L. L., T., Cross-comparison of macroscopic fundamental diagram estimation methods. Procedia - Social and Behavioral Sciences, , No. 20, 417-426, 2011.

[18] Geroliminis, S. J., N., Properties of a well-defined macroscopic fundamental diagram for urban traffic. Transportation Research B, , No. 45(3), 605-617, 2011.

[19] Knoop, S. V. L. H., V. Hoogendoorn, Routing Strategies based on the Macroscopic Fundamental Diagram. Transportation Research Board, , No. 91st Annual Meeting, 2012.

[20] Cassidy, J. K., M.J. and C. Daganzo, Macroscopic Fundamental Diagrams for freeway networks : Theory and observation. Transportation Research Record, , No. 2260, 8-15, 2011.

[21] Daganzo, G. V. G. E., C.F., Macroscopic relations of urban traffic variables: bifurcations, multivaluedness and instability. Transportation Research B, , No. 45(1), 278-288, 2011.

[22] Yung-Cheng (Rex) Lai, Y.-J. L., Yun-Hsuan Liu, Development of Base Train Equivalents for Headway-Based Analytical Railway Capacity Analysis. RailCopenhagen, 2013. 